\title{
Bioavailability of Tea Catechins and Its Improvement
}

\author{
Zhuo-Yu Cai ${ }^{1}$, Xu-Min Li ${ }^{1}$, Jin-Pei Liang ${ }^{2}$, Li-Ping Xiang ${ }^{3}$, Kai-Rong Wang ${ }^{4}$, Yun-Long Shi ${ }^{1}$, \\ Rui Yang ${ }^{1}$, Meng Shi ${ }^{1}$, Jian-Hui Ye ${ }^{1}$, Jian-Liang Lu ${ }^{1}$, Xin-Qiang Zheng ${ }^{1, *}$ and \\ Yue-Rong Liang ${ }^{1, *(D)}$ \\ 1 Tea Research Institute, Zhejiang University, Hangzhou 310058, China; 21716160@zju.edu.cn (Z.-Y.C.); \\ 21616096@zju.edu.cn (X.-M.L.); 11516051@zju.edu.cn (Y.-L.S.); 21616106@zju.edu.cn (R.Y.); \\ 11616052@zju.edu.cn (M.S.); jianhuiye@zju.edu.cn (J.-H.Y.); jllu@zju.edu.cn (J.-L.L.) \\ 2 Intellectual Property Office of Lanshan District, Rizhao 543003, China; liangjinpeirz@163.com \\ 3 National Tea and Tea Product Quality Supervision and Inspection Center (Guizhou), Zunyi 563100, China; \\ xlping6009@126.com \\ 4 Ningbo Extension Station of Forestry \& Speciality Technology, Ningbo 315012, China; \\ wkrtea321hjytea@163.com \\ * Correspondence: xqzheng@zju.edu.cn (X.-Q.Z.); yrliang@zju.edu.cn (Y.-R.L.); \\ Tel.: +86-571-8898-2704 (X.-Q.Z. \& Y.-R.L.)
}

Received: 3 August 2018; Accepted: 12 September 2018; Published: 13 September 2018

\begin{abstract}
Many in vitro studies have shown that tea catechins had vevarious health beneficial effects. However, inconsistent results between in vitro and in vivo studies or between laboratory tests and epidemical studies are observed. Low bioavailability of tea catechins was an important factor leading to these inconsistencies. Research advances in bioavailability studies involving absorption and metabolic biotransformation of tea catechins were reviewed in the present paper. Related techniques for improving their bioavailability such as nanostructure-based drug delivery system, molecular modification, and co-administration of catechins with other bioactives were also discussed.
\end{abstract}

Keywords: Camellia sinensis; catechins; bioavailability; nanoparticle; interaction

\section{Introduction}

Increased evidence has expanded the role of green tea from a traditional beverage to a source of bioactive ingredients with many health benefits. Green tea is rich in catechins comprised of more than eight polyphenolic compounds. According to different sources, the most abundant catechins in tea are (-)-epigallocatechin gallate (EGCG) and (-)-epigallocatechin (EGC) [1,2]. In recent years, EGCG has attracted significant research interest due to its beneficial health effects including antioxidation [3], anti-diabetes [4], anti-inflammation [5-7] and anti-tumorigenesis activity [8]. Therefore, EGCG has recently gained the attention of scientists for implementation as a therapeutic alternative for treating some diseases.

There have been many in vitro studies showing that EGCG possesses antioxidant properties and exhibits favorable effects on gene expression, signal transduction and other cell functions [9]. Numerous potential mechanisms have been proposed to explain the healthy benefits of tea catechins, including improving antioxidative activity, suppressing adipocyte differentiation, regulating the tumor-suppressor microRNAs, inhibiting hepatocyte growth factor receptor activity, inhibiting Ikb kinase activity, etc. [3,10-13]. In vitro studies showed that the effective concentrations of EGCG ranged from 1 to $100 \mu \mathrm{mol} / \mathrm{L}$. However, the peakplasma levels of tea catechins were usually in the sub-or low-micromolarrange in human subjects or animals following oraladministration of green tea catechins $[14,15]$, which was lower than the effective concentration of in vitro tests. Therefore, the therapeutic effect is limited, owing to poor stability in the gastrointestinal tract and 
limited membrane permeability across the intestine [16-18]. Their therapeutic potential is limited by its poor systemic absorption following oral administration, including low absorption, poor pharmacokinetics and bioavailability, scarce biodistribution, first-pass metabolism, trivial penetration and low accumulation in the related tissues of the body, or low targeting efficacy. The inconsistency between catechins' superior in vitro biological activity and low absorption in in vivo studies can also be attributed to its low stability, which lead to the formation of degradation products and pro-oxidant molecules [19]. Catechins are unstable under physiologic conditions and they could be rapidly degraded or metabolized through interactions with the hydroxyl groups on the phenol rings [19]. Even if administered intravenously, catechins were partially degraded before reaching the target tissues [20]. EGCG needs to work at a relatively high concentration to target related molecules and to affect disease-related cellular processes $[9,21]$. It is believed that taking green tea polyphenol products in amounts equivalent to the EGCG content in 8-16 cups of green tea daily may mitigate the poor bioavailability of EGCG [22]. The systemic availability of EGCG increased at higher doses, possibly due to saturable pre-systemic elimination of orally administered green tea polyphenols (GTPs) [23]. However, it is obviously not a good idea to use excessive dose of catechins for improving effectiveness. Studies from experimental animals and epidemiological surveys have shown that GTPs have a dose-dependent toxicology [24]. Tea polyphenols are antioxidants, but they can also generate reactive oxygen species (ROS). It was observed that moderate doses of tea polyphenols induced finite amount of lower level of ROS which may also activates nuclear factor erythroid 2-related factor 2 (Nrf2) to activate antioxidant and detoxifying enzymes, and then attenuate oxidative stress, whilst excessive amounts of GTPs probably induced a pro-oxidant effect, resulting in induced toxicity effect [9].

The present paper comprehensively reviews the mechanisms leading to low absorption, poor permeability and less stability of tea catechins and also describes the potential for improving the bioavailability of tea catechins through new techniques such as nanoparticle-based delivery systems, structurally modified molecule of catechins, co-administration with other drugs or bioactives. Furthermore, the challenges and future research directions are also discussed.

To collect the related references, computerized systematic literature searches were conducted inWeb of Science and Google Scholar databases to retrieve the pertinent studies and reviews. The search keywords used were tea catechins or tea polyphenolsor epigallocatechin gallate (EGCG) in combination with the terms absorption, bioavailability, metabolism, or nanoparticles, chitosan, prodrugs, peracetylate, and synergistic as well as the terms improvementand enhancement. The papers published in the English languagewere exclusively evaluated. No other limitations were applied. The literatures were combed and divided into four main categories: (a) pharmacokinetics of tea catechins, (b) drug delivery system, (c) molecular modification, and (d) synergistic effect with other drugs. Thus, the review is structured. First, into a discussion on the bioavailability of catechins, and then, to provide more thorough insights into the way and mechanism to improve.

\section{Absorption and Metabolism of Tea Catechins}

Only a small fraction of tea catechins present in the intestinal tract after drinking tea can be absorbed, and therefore considered to be bioavailable, i.e., appearing in the blood and tissues or reaching the systemic circulation. The latest study demonstrates that concentration of catechins in green tea infusions is about $3250-4410 \mathrm{mg} / \mathrm{L}$ [2]. Tests showed that less than $5 \%$ of the orally administered dose of tea catechins reached the systemic circulation in rat $[25,26]$ and approximately $1.68 \%$ of ingested catechins were present in human's plasma $(0.16 \%)$, urine $(1.1 \%)$ and feces $(0.42 \%)$ after tea ingestion over $6 \mathrm{~h}$ [27]. The pharmacokinetics study showed that after oral administration of tea to rats, about $14 \%$ of (-)-epigallocatechin (EGC), $31 \%$ of (-)-epicatechin (EC), and $<1 \%$ of (-)-epigallocatechin-3-gallate (EGCG) appeared in the blood [28]. For humans, after administration of $3 \mathrm{~g}$ of decaffeinated green tea, the maximum plasma concentration for EGCG, EGC, and EC were 0.57, 1.60 , and $0.6 \mu \mathrm{M}$, respectively [29]. 
A fraction of the ingested tea catechins undergoes extensive metabolism by phase II enzymes, such as UDP-glucuronosyltransferases (UGTs), sulphotransferases (SULTs) and catechol-O-methyltransferase (COMT) before and after being absorbed predominantly in the small intestine and in liver [30], with the remained catechins entering the colon. Partial catechins pass into colon with the secreted bile in an enterohepatic recirculation process, where they are degraded into different flavonoid rings by the resident microorganisms. The metabolites identified in humans include glucuronide and sulfate conjugates, methylated tea catechin conjugates, and microflora-mediated ring fission products and phenolic acid catabolites [31]. The catabolized phenolic acids can be re-absorbed into the circulation or excreted into urine. Stalmach et al. $[32,33]$ reported that when human subjects with an ileostomy consumed green tea solution containing $634 \mu \mathrm{mol}$ of catechins, $70 \%$ of the ingested catechins was detected in the ileal fluid during 0-24 h after administration, in which 33\% was in the form of parent compounds and $37 \%$ was the metabolites with 23 compounds in total. Sixteen of the metabolites were found in plasma, in the forms of principally methylated, sulphated and glucuronide conjugates of catechins, with peak catechins concentration 101-256 nM in plasma. Catechins and their conjugated metabolites, catabolized small molecular phenolic acids can be distributed in various organs and tissues, where they perform various biological actions.

No specific receptors on the surface of small intestinal epithelial cells have been found to carry EGCG into cells. Thus, the mechanism for catechins being transported across epithelium is principally based on passive diffusion, including paracellular and transcellular diffusions. Cell studies have also suggested that EGCG underwent active efflux after absorption by ATP-depended proteins. EGCG and its metabolites were served as common substrates for two important protein efflux pumps including the multidrug resistance-associated protein (MRP) efflux pumps [34] and the P-glycoprotein (P-gp) [35,36], by which majority of the absorbed catechins were pumped back to the extracellular or intestinal space, resulting in limitation of their bioavailability.

In brief, many processes including chemical degradation, microbial metabolism, intestinal and hepatic metabolism, membrane permeability, and transporter-mediators may influence the bioavailability of catechins (Figure 1).

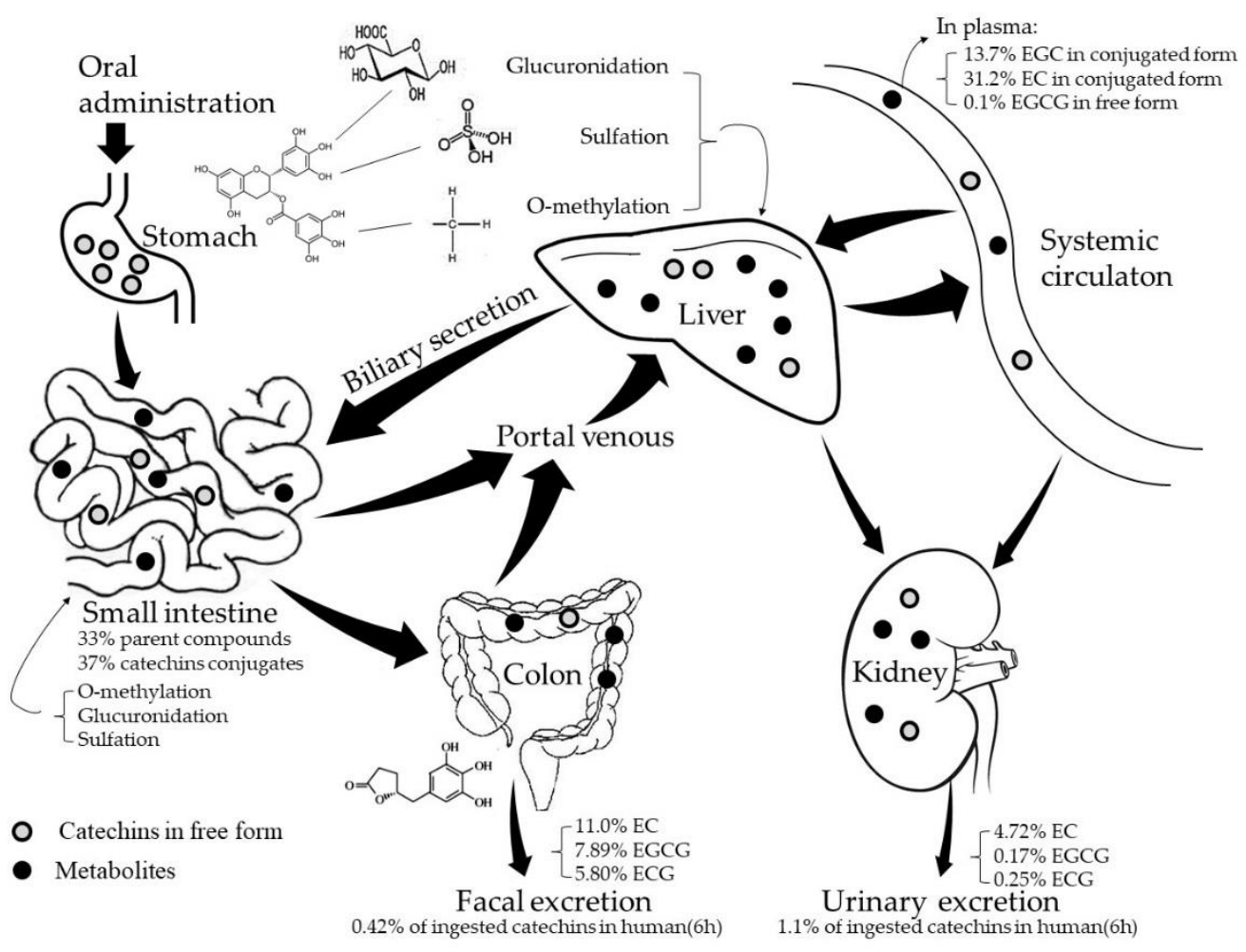

Figure 1. Schematic diagram of metabolism of green tea catechins $[28,32,33,37]$. 


\section{Improving the Bioavailability of Catechins}

\subsection{Nanostructure-Based Drug Delivery System}

Nanostructure-based drug delivery system is one of the fastest-emerging areas in improving the bioavailability of drugs. Many studies showed promising EGCG-loaded nano-carriers with sustained release and improved bioavailability even at much lower doses than conventional preparations. Encapsulation materials including lipids [38,39], proteins [40,41], carbohydrate [42] can be used as carriers and exert improving effects on the bioavailability of diet catechins including EGCG, via enhancing its solubility, preventing its degradation in the intestinal environment, elevating the permeation in small intestine, resulting in an increased concentration in the bloodstream $[43,44]$.

\subsubsection{Protein-Based Carriers}

The stability of EGCG was improved when bound to bovine serum albumin (BSA) [45]. Both EGCG ovalbumin-dextran conjugate nanoparticle and chitosan coated BSA-EGCG nanoparticle showed significantly higher apparent permeability coefficient compared to free EGCG in solution, resulting in an improvement of the EGCG absorption [46,47]. The radioprotection effect of chitosan coated BSA-polyphenols nanoparticles by oral administration in mice was significantly higher than that of free polyphenols [48].

A catechin-loaded nanoemulsion-based nanogel showed sustained release profile, resulting in enhanced photoprotection potential to skin due to its improved permeability as well as bioavailability through transdermal route, compared to the conventional gel [49], in which gelatin showed higher bioaccessibility and antioxidant activity than chitosan [50].

Milk proteins, containing caseins and whey proteins, were considered as ideal carriers for delivering catechins. Sodium caseinate adsorbed at the oil water interface, can load high ratios of EGCG [51,52]. Casein micelles can be used as protective carriers for EGCG in foods. It was demonstrated that nanoencapsulation of EGCG in casein micelles did not diminish antiproliferative activity of the catechins on colon cancer cells, compared with free form EGCG [53]. Accordingly, casein micelle is considered to be an ideal platform for catechin delivery while the binding of caseins with EGCG would not affect the bioaccessibility of EGCG.

Other proteins such as corn zein protein [41,54], soy protein [55] and rice bran protein isolate [56] were confirmed to improve the stability, bioaccessibility and permeability of catechins, and could be employed as satisfactory carriers for tea catachins. Incorporation of EGCG in zein fiber-forming solution through hydrogen bonding, hydrophobic interactions, and physical encapsulation enhanced the stabilization of EGCG [41].

The presence of hydroxyl groups in EGCG contributes to its strong affinity to proteins by enhancing its interactions with proteins. Although the interactions between catechins and proteins alter the protein structure [57], leading to partial decrease in antioxidant activity of EGCG, the protein protects EGCG against degradation [58].

\subsubsection{Carbohydrate-Based Carriers}

Delivery systems based on carbohydrates, including chitosan, cellulose polymers, starch-based materials, gum arabic and sodium alginate, have been widely used in pharmaceutical field to enhance absorption of bioactive compounds, owing to their biodegradability, biocompatible and non-toxic properties. Chitosan is the most widely used material as an EGCG carrier, for it is the most abundant alkaline natural polysaccharide with good biological intermiscibility and film-forming properties. Swiss Outbred mice oral administration of the chitosan-tripolyphosphate nanoparticles enhanced the plasma exposure of total EGCG by a factor of 1.5 relative to free EGCG [42]. In addition to chitosan, digestive stability of green tea catechins encapsulated into $\gamma$-cyclodextrin $(\gamma-C D)$ or coated with hydroxypropylmethyl cellulose phthalate (HPMCP) was enhanced by $65.56 \%$ or $57.63 \%$, respectively. Formulated catechins followed by encapsulation into $\gamma$-cyclodextrin significantly increased intestinal 
transport by $22.98 \%$ and $23.23 \%$ when coated with for S-HPMCP and L-HPMCP, respectively [59]. Bioavailability of the catechins increased by 4.08 and 11.71 times when coated with S-HPMCP and L-HPMCP, respectively, indicating that coating with HPMCP could be an effective way to improve the digestive stability and intestinal transport of catechins [60]. It is demonstrated that HPMCP will not dissolve in the acidic juices of the stomach $(\mathrm{pH} \approx 3)$, but it will dissolve in the alkaline ( $\mathrm{pH} \approx 7-9$ ) conditions of the small intestine. There was study showing that intestinal absorption of the enteric-coated ingredient by HPMCP increased due to its controlling both the erosion rate and the length of intestinal segment [59]. Overall, many carbohydrates can stabilize formulations and provide protection and sustained release of the EGCG.

\subsubsection{Lipid-Based Carriers}

Lipid carriers incorporating drugs have been found to improve the absorption and circulation time in the body versus stand-alone compounds [61] and it is also used as nanodelivery systems to encapsulate green tea extract. Tea polyphenol nanoliposomes improved the stability of tea polyphenol in alkaline solution, resulting in better sustained release property, with equivalent antioxidant activities [62]. EGCG encapsulated in liposomes increased drug deposition by 20-fold as compared to the free form [63]. The same results have been confirmed by various tests. When the catechins encapsulated on liposomes were orally administered to rats, the catechinlevel in blood was enhanced at the later stage compared with the aqueous solution control. Additionally, elastic liposomes showed 2.9and 2.7-fold higher catechin accumulation in the cerebral cortex and hippocampus, respectively [64]. The degenerations of in vitro antioxidant activities of EGCG were effectively slowed by nanoliposome encapsulation [39]. Test on niosomes, a kind of novel vesicular system with a bilayer containing nonionic surfactants and cholesterol, demonstrated that drug-loaded niosomes had stronger stability and lower toxicity than control, resulting in a significantly improved absorption compared to their free forms [36].

\subsubsection{Mechanism by Which Nano-Carriers Improving the Bioavailability of Catechins}

Catechins are unstable and highly susceptible to ambient conditions like oxygen, $\mathrm{pH}$ changes, metal ions and other stress factors. Nanoparticle-based delivery systems are believed to be plausible options to protect catechins against harsh conditions. The EGCG loaded on lipids showed better stability. Many food formulations are water based, the presence of EGCG on liposomes had the potential to promote the formation of hydrogen bonds between hydrophilic catechins and polar head groups [65]. In vitro study shows that chitosan-tripolyphosphate (TPP) nanoparticles improved the stability of EGCG in alkaline solution [66]. EGCG encapsulated in chitosan exhibited higher stability than free EGCG in simulated gastrointestinal (GI) tract. It is hypothesized that the interaction between positively charged chitosan and negatively charged tea catechins formed polyelectrolyte matrices with stable spherical shape and $\mathrm{pH}$-tunable dimensions, which overcame the poor gastrointestinal stability of tea catechins [67]. Moreover, transendothelial electrical resistance (TEER) experiments showed that the nanoparticles with a positive surface charge transiently opened the reversible tight junctions between Caco-2 cells and thus promoted the paracellular transport of tea catechins [68]. However, it is considered that the mechanism by which absorption of catechins is enhanced is likely due to the improved stabilization of catechins after encapsulation, but not through the effects of chitosan nanoparticles on intestinal paracellular or passive transcellular transport processes or on efflux proteins [69].

Although the half-life period of EGCG (5.0-5.5 h) is about two times longer than that of EGC or EC (2.5-3.4 h), it is still too short to exert clinical effect. Sustainable and control release of catechins is a feasible way to improve their bioavailability. However, sustained release capacities of EGCG depend on the carrier systems. About 6.0\% and 12.6\% EGCG was released from EGCG nanoliposomes at 6 and $24 \mathrm{~h}$, respectively [39]. When EGCG was loaded on niosomes, the residual EGCG increased from $3 \%$ to $49 \%$ after incubation in simulated intestinal fluid for $2 \mathrm{~h}$, meanwhile the niosomes loaded 
EGCG exhibited stronger antioxidant ability than free EGCG during intestinal digestion [70]. Chitosan coatings could control the release pattern of EGCG from the BSA-EGCG nanoparticles, with slow release of EGCG in the simulated acidic gastric juice conditions but faster release in simulated alkaline intestinal fluid [46,71].

Some nanoparticles not only enhance the stability of EGCG, but also improve the membrane permeation. Song [36] reported that the transport of drug-loaded niosomes may be contributed to the endocytotic pathway. The interaction of EGCG with the phosphate moiety of dimyristoyl-phosphatidylcholine (MDPC) lipid [72] which is one of the components of the cell membrane makes it easier to cross the membrane. Thus, entrapping EGCG into liposomes could protect EGCG from enzymatic degradation and improve the membrane permeation. Accordingly, liposomes are considered to be a good carrier to improve EGCG adsorption via oral ingestion.

In addition, the drug loaded on nanoparticles can protect the core material from adverse environmental conditions, delay its degradation in the humoral environment, make it easily penetrate various barriers to reach the target organs, which contributes to the controlled liberation of the drugs and improvement of the drug bioavailability. The effects of EGCG nanoparticles are listed in Table 1. 
Table 1. Various carriers of catechins and their improvement of effectiveness.

\begin{tabular}{|c|c|c|c|}
\hline Materials of Carrier & Bioactive & Improvement of Effectiveness & Ref. \\
\hline Chitosan and TPP & EGCG & Improved stability and increased plasma concentrations of EGCG & {$[42,66]$} \\
\hline Chitosan & Catechin and EGCG & Enhanced the intestinal absorption of catechins & [69] \\
\hline Carboxymethyl chitosan & EGCG & Improved stability and sustained release. & [73] \\
\hline Chitosan and $\gamma$-glutamic acid & Catechins & Increased the paracellular transport of catechins with effective antioxidant activity. & [68] \\
\hline Chitosan and polyaspartic acid & EGCG & Improved the effectiveness of EGCG against rabbit atherosclerosis. & [74] \\
\hline Chitosan and caseinophosphopeptides & EGCG & Enhanced the intestinal permeability of catechins & [75] \\
\hline Beta-chitosan & Catechins & Improved the antibacterial activity & [76] \\
\hline 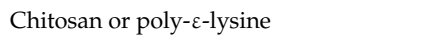 & EGCG & Improved the stability of EGCG and improved the permeability across intestine & [47] \\
\hline Chitosan & $\mathrm{TP}$ & Improved the level of radioprotection of TP. & [48] \\
\hline HPMCP or $\gamma$-CD & Catechins & Increased intestinal transport. & [59] \\
\hline HPMCP & Catechins & Improved the stability of catechins and increased intestinal transport. & [60] \\
\hline Lipsomes & Catechins & Enhanced the transdermal delivery of catechins. & [77] \\
\hline Lipsomes & Green tea extract & Improved the stability of catechins. & [38] \\
\hline Lipsomes & TP & Improved the stability of catechins. & [62] \\
\hline Liposome & Catechins & Inducted greater basal cell carcinomas death at lower concentrations. & [63] \\
\hline Nanolipsomes & EGCG & Induced apoptosis and inhibited proliferation of MCF7 breast cancer cells. & [78] \\
\hline Nanolipsomes & Catechins & Improved the antioxidant activity & [79] \\
\hline Nanostructured lipid & EGCG & $\begin{array}{l}\text { Inhibitd atherosclerotic lesion development through decreasing macrophage cholesterol content and monocyte chemoattractant } \\
\text { protein-1 expression. }\end{array}$ & [80] \\
\hline Nanolipidic & EGCG & Improved $\alpha$-secretase inducing ability of EGCG for the treatment of Alzheimer's disease. & [81] \\
\hline Nanoethosomes & EGCG & Enhancing the skin permeability. & [82] \\
\hline Niosomes & EGCG & Improved the stability of catechins and exhibited stronger antioxidant ability. & [70] \\
\hline Ovalbumin & EGCG & Enhanced the apparent permeability coefficient of EGCG on Caco-2 monolayers & [46] \\
\hline Casein micelles & EGCG & Improved the stability of catechins, and decreased the proliferation of HT-29 cancer cells without affecting the bioefficacy of EGCG. & [83] \\
\hline Casein micelles & Catechins & Improved the stability of catechins, and decreased the proliferation of HT-29 cancer cells in a manner similar to that of free EGCG. & [53] \\
\hline Zein & EGCG & Improved the stability of EGCG. & [41] \\
\hline Rice bran protein isolate & Catechins & Improved the stability of catechins. & [56] \\
\hline$\beta$-lactoglobulin & EGCG & Protected antioxidant activity of EGCG & [84] \\
\hline Selenium nanoparticles and Tet-1 peptide & EGCG & Inhibited amyloid- $\beta$ fibrillation and disaggregate preformed amyloid $-\beta$ fibrils into nontoxic aggregates. & [85] \\
\hline poly(lactide-co-glycolide) & EGCG & Showed a superior ability to prevent DMBA-induced DNA damage at much lower concentrations & [86] \\
\hline
\end{tabular}

TPP: tripolyphosphate; BSA: bovine serum albumin; HPMCP: hydroxypropyl methyl cellulose phthalate; $\gamma$-CD: $\gamma$-cyclodextrin; DMBA: 7,12-dimethylbenzanthracene. 


\subsection{Molecular Modification}

Biochemically, conjugation of the free hydroxyl groups surrounding the molecules influences the efficacy of ingested tea catechins. A molecular modification method using peracetate acid can be used to protect the reactive hydroxyl groups of EGCG. Synthesized peracetate-protected EGCG (AcEGCG, Figure 2) was found to be much more stable than free EGCG under slightly alkaline physiological conditions and showed greater efficacy in proteasome inhibition and induction of cancer cell death [87].<smiles>O=C(OC1Cc2c(O)cc(O)cc2OC1c1cc(O)c(O)c(O)c1)c1cc(O)c(O)c(O)c1</smiles>

EGCG

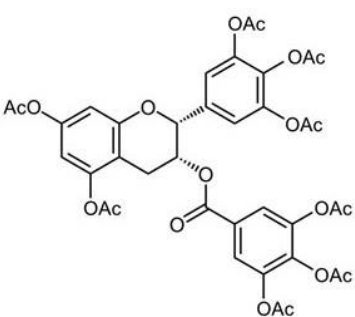

Peracetylated EGCG

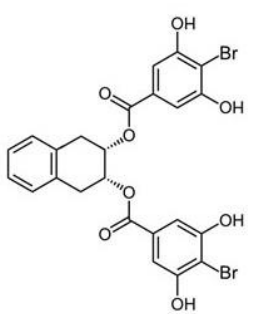

Synthetic EGCG analogs 4

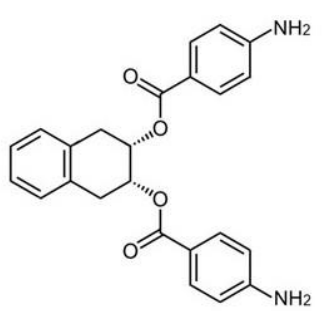

Synthetic EGCG analogs 6

Figure 2. Molecular structures of (-)-epigallocatechin-3-gallate (EGCG) and EGCG-based prodrugs and analogs.

It was reported that AcEGCG increased EGCG stability, resulting in increased bioavailability and enhanced inhibition on the proteasome and growth of breast tumor. Peracetylation also increased the bioavailability of EGCG in esophageal and colon cancer cells [88], and the AcEGCG showed much higher potency to prevent dextran sulfate sodium (DSS)-induced colitis than free EGCG $[6,89]$. These studies suggest that AcEGCG has improved biological activity in vivo. This effect is accomplished by making hydroxyl groups unavailable for biotransformation or oxidative degradation. AcEGCG increased the intracellular levels of EGCG as a result of increased cell uptake, and convert intracellularly into EGCG in the presence of esterase, which could be detected within 5 min following incubation of AcEGCG in mouse plasma at $37^{\circ} \mathrm{C}$. However, once EGCG was released from AcEGCG, it is then subject to biotransformation and efflux at a rate similar to free EGCG [88].

Acetate protection of EGCG's phenol groups is a useful tool for enhancing the stability and improving the bioavailability of EGCG. Furthermore, other chemical modifications that can improve the physiochemical properties of EGCG or reduce its biotransformation may be also useful in improving its bioavailability (Table 2). 
Table 2. Molecular modification of EGCG and its effects.

\begin{tabular}{|c|c|c|c|c|}
\hline Molecular Modification & Tested Cell Lines & Cancer Type & Major Effects & Ref. \\
\hline \multirow{8}{*}{ Peracetylated EGCG } & Jurkat T & Leukemic & $\begin{array}{l}\text { Being more stable than free EGCG at neutral } \mathrm{pH} \text { and showing greater efficacy } \\
\text { in proteasome inhibition and cell death induction. }\end{array}$ & [87] \\
\hline & KYSE150, HCT116 & Esophageal and colon & $\begin{array}{l}\text { Increasing the biological potency in vitro and the bioavailability of EGCG in } \\
\text { esophageal or colon cancer cells. }\end{array}$ & [88] \\
\hline & & Colon & Showing stronger prevention potency to DSS-induced colitis than free EGCG. & [89] \\
\hline & CD34+ & Skin & $\begin{array}{l}\text { Preventing skin carcinogenesis by suppressing the PKD1-dependent signaling } \\
\text { pathway in CD34+ skin stem cells and skin tumors }\end{array}$ & [90] \\
\hline & MDA-MB-231 & Breast & $\begin{array}{l}\text { Increasing the bioavailability, stability, and proteasome inhibition and } \\
\text { anticancer activities of EGCG in human breast cancer cells and tumors. }\end{array}$ & [91] \\
\hline & CWR22R & Prostate & $\begin{array}{l}\text { Being more stable, increasing the therapeutic anticancer effects in } \\
\text { androgen-independent prostate cancer }\end{array}$ & [92] \\
\hline & & \multirow{2}{*}{ Endometrium } & $\begin{array}{l}\text { Inhibiting the growth, development and angiogenesis of experimental } \\
\text { endometriosis in mice, with improved efficacy, bioavailability, anti-oxidation } \\
\text { and anti-angiogenesis capacities. }\end{array}$ & [93] \\
\hline & & & $\begin{array}{l}\text { Inhibiting tumor angiogenesis through downregulation of VEGFA and HIF1 } \alpha \\
\text { in tumor cell and chemokine(C-X-C motif) ligand } 12 \text { in host stroma. }\end{array}$ & [94] \\
\hline $\begin{array}{l}\text { Synthetic EGCG analogs } 4 \text { and } 6 \\
\text { (Figure 2) }\end{array}$ & MDA-MB-231 & Breast & $\begin{array}{l}\text { Activating AMPK, with inhibition of cell proliferation, up-regulation of the } \\
\text { cyclin-dependent kinase inhibitor p21, down-regulation of mTOR pathway, } \\
\text { and suppression of stem cell population in human breast cancer cells. }\end{array}$ & [95] \\
\hline
\end{tabular}




\subsection{Co-Administration of Catechins with Other Bioactive Components}

It was found that a mixture of tea catechins and ascorbic acid significantly increased tea catechins' recovery in a simulated in vitro digestion system [96]. Absorption of EGC and EGCG was significantly enhanced in formulations containing ascorbic acid and carbohydrate derives. Also, accumulation of EGC, EGCG and ECG by Caco-2 cells was significantly increased in formulations containing ascorbic acid and sucrose $[59,97,98]$.

Apart from ascorbic acid, many other bioactive compounds show synergistic interactions with tea catechins. A major challenge for cancer chemotherapy and radiotherapy is time-dependence multi-drug resistance (MDR), as well as treatment interruptions caused owing to various side effects. To overcome this shortcoming, developing novel combination therapies for chemotherapy and bioactive dietary compounds will be a trend in future. The combination of catechins with other drugs which shows synergistic effects might be a promising approach.

Tea catechins showed a good coordination with some conventional anticancer drugs. The presence of EGCG significantly increased the pharmacokinetics of orally administered tamoxifen, which was attributed to the decrease in first-pass metabolism in the intestine and liver by inhibiting P-glycoprotein and CYP3A by EGCG [99]. Kitagawa et al. [100] reported that EGCG inhibited the efflux of P-gp substrates, verapamil and quercetin in KB-C2 cells, since the effects of EGCG were stronger than those of verapamil and quercetin, leading to the elevation of substrate accumulation. NS-398, a selective cyclooxygenase-2 inhibitors, showed an increased efficacy for inhibiting cancer cells when it was used jointly with EGCG by promoting apoptosis induction, inhibiting nuclear factor-Kb [101]. The combination of EGCG with sulindac significantly up-regulated expression of growth arrest related genes, with DNA damage-inducible 153 (GADD153) increasing by about 12-fold and p21WAF1 increasing by 3-fold; meanwhile no effects were observed when EGCG or sulindac was used alone [102] (Table 3). 
Table 3. Improvement of biological activities by co-administration catechins with other complementary bioactives.

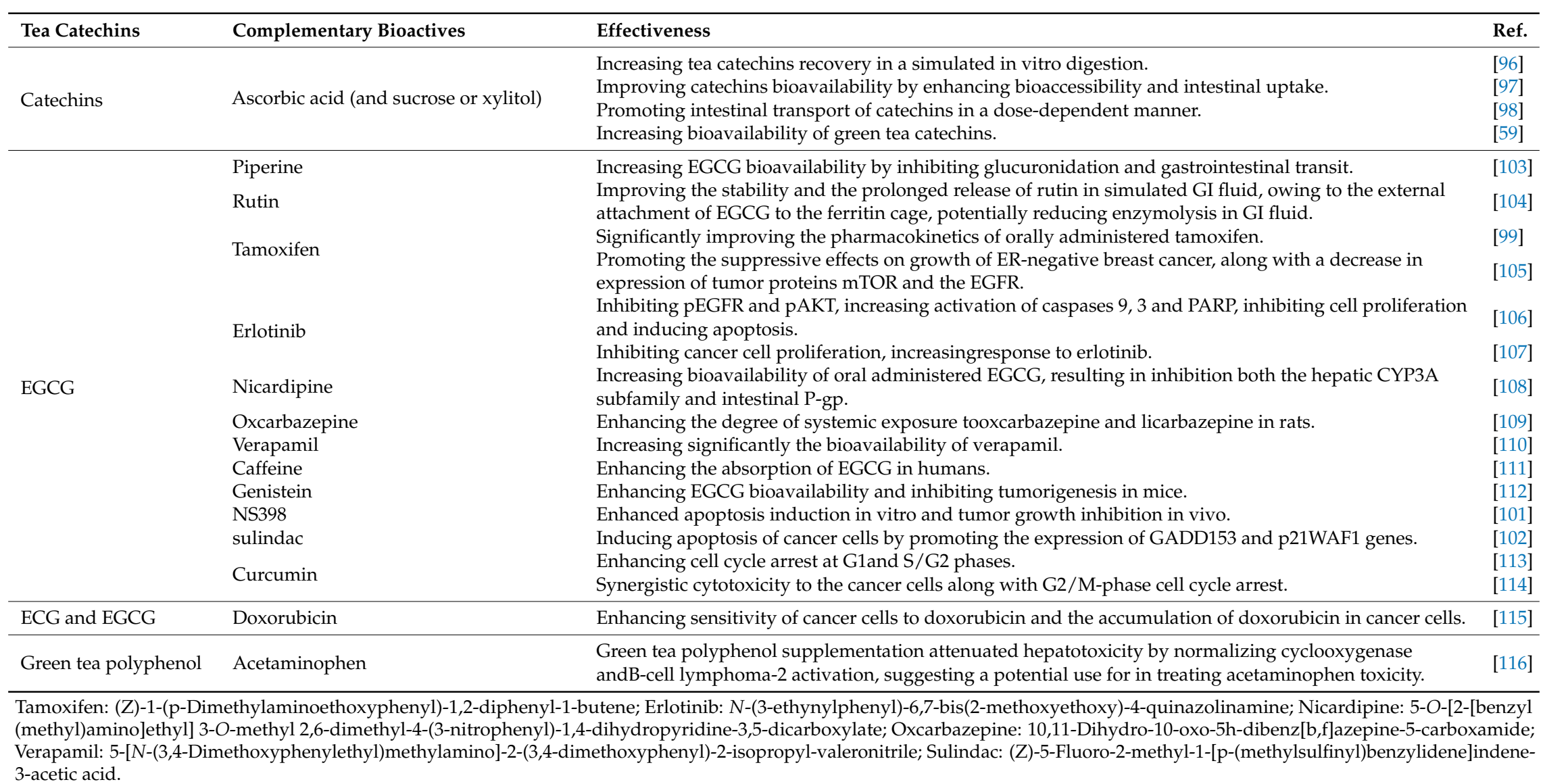




\section{Conclusions and Future Expectations}

Low bioavailability of green tea catechins is an important factor leading to the observed inconsistency between in vitro and in vivo studies. Stability, absorption rate and efflux influence the bioavailability. Extreme $\mathrm{pH}$ conditions in the stomach and intestinal tract as well as related digestive enzymes are confirmed to be factors inducing instability including degradation and conjugation of catechins. Catechins are considered to be transported across intestinal epithelium principally by passive diffusion, including paracellular and transcellular diffusions because no specific receptors on the surface of small intestinal epithelial cells have been found to carry EGCG into cells, which is the main reason why the absorption rate of catechins is low. The active efflux of partial absorbed catechins decreases the plasma catechins concentration [43].

The bioavailability of catechins can be improved by nanostructure-based drug delivery systems, molecular modification and co-administration with some other bioactive ingredients. Encapsulation of tea catechins on protein-based, carbohydrate-based and lipid-based nanoparticles improved stability, sustainable release and cell membrane permeation of catechins, resulting in increased bioavailability. Molecular modification such as synthesizing peracetylated EGCG (AcEGCG) protects hydroxyl groups on EGCG from oxidative degradation until it is deacetylated into its parent EGCG by esterases in cells [87], which decreases biotransformation and efflux of EGCG. Co-administrating or formulating catechins with appropriate other drugs or bioactives will produce a synergism effects through interaction of catechins with the selected drugs, resulting in improvement of absorption and inhibition of efflux transporter $[35,78,99,100]$.

There are still great expectations in the fields of bioavailability research of tea catechins. Disease-targeting and multiple molecular targeting are expected to be improved so as to find more potent, stable and specific active formulation of catechins [102]. Targeted delivery with rapid release of a toxic dose level is expected in cancer treatment. However, sustainable release of low dosage EGCG over a longer period of time is needed for treatment of chronic diseases like atherosclerosis or neurodegeneration. Furthermore, improving skin permeability is desired in the cosmetic field. More importantly, the effectiveness of these improved techniques requires further clinical validation.

Author Contributions: Z.-Y.C.: Literatures research, Figures 1 and 2. Introduction; X.-M.L.: 2. Absorption and metabolism of tea catechins; J.-P.L.: Section 3.1.1. Protein-based carriers; L.-P.X.: Section 3.1.2. Carbohydrate-based carriers; K.-R.W.: Section 3.1.2. Carbohydrate-based carriers; R.Y.: Table 1; M.S.: Table 2; J.-H.Y.: Table 3; J.-L.L.: Section 3.1.3. Lipid-based carriers; X.-Q.Z.: Literature search and project design, Abstract and Section 3.1.4. Mechanism by which nanocarriers improving the bioavailability of catechins; Y.-R.L.: Project design, Section 3.2. Molecular modification and Section 3.3. Co-administration of EGCG with other bioactive components and Section 4. Conclusions.

Funding: This study was supported by grants from the Science Technology Department of Zhejiang Province (Project No. 2016C02053-5) and the China Agriculture Research System (Tea) (CARS-19).

Acknowledgments: The authors acknowledge the Science Technology Department of Zhejiang Province for financial support to this work (Project No. 2016C02053-5). This work was also financially supported by the China Agriculture Research System (Tea) (CARS-19).

Conflicts of Interest: The authors declare no conflict of interest.

\section{References}

1. Nagle, D.G.; Ferreira, D.; Zhou, Y.D. Epigallocatechin-3-gallate (EGCG): Chemical and biomedical perspectives. Phytochemistry 2006, 67, 1849-1855. [CrossRef] [PubMed]

2. Koch, W.; Kukula-Koch, W.; Komsta, Ł.; Marzec, Z.; Szwerc, W.; Głowniak, K. Green tea quality evaluation based on its catechins and metals composition in combination with chemometric analysis. Molecules 2018, 23, 1689. [CrossRef] [PubMed]

3. Miyazawa, T. Absorption, metabolism and antioxidative effects of tea catechin in humans. Biofactors 2000, 13, 55-59. [CrossRef] [PubMed]

4. Fu, Q.Y.; Li, Q.S.; Lin, X.M.; Qiao, R.Y.; Yang, R.; Li, X.M.; Dong, Z.B.; Xiang, L.P.; Zheng, X.Q.; Lu, J.L.; et al. Antidiabetic effects of tea. Molecules 2017, 22, 849. [CrossRef] [PubMed] 
5. Cavet, M.E.; Harrington, K.L.; Vollmer, T.R.; Ward, K.W.; Zhang, J.Z. Anti-inflammatory and anti-oxidative effects of the green tea polyphenol epigallocatechin gallate in human corneal epithelial cells. Mol. Vis. 2011, 17, 533-542. [PubMed]

6. Oz, H.S.; Chen, T.S.; McClain, C.J.; de Villiers, W.J. Antioxidants as novel therapy in a murine model of colitis. J. Nutr. Biochem. 2005, 16, 297-304. [CrossRef] [PubMed]

7. Oz, H.S.; Chen, T.; de Villiers, W.J.S. Green tea polyphenols and sulfasalazine have parallel anti-inflammatory properties in colitis models. Front. Immunol. 2013, 4, 132. [CrossRef] [PubMed]

8. Xiang, L.P.; Wang, A.; Ye, J.H.; Zheng, X.Q.; Polito, C.A.; Lu, J.L.; Li, Q.S.; Liang, Y.R. Suppressive effects of tea catechins on breast cancer. Nutrients 2016, 8, 458. [CrossRef] [PubMed]

9. Yang, C.S.; Wang, X.; Lu, G.; Picinich, S.C. Cancer prevention by tea: Animal studies, molecular mechanisms and human relevance. Nat. Rev. Cancer 2009, 9, 429-439. [CrossRef] [PubMed]

10. Roberto, B.S.; Macedo, G.A.; Macedo, J.A.; Martins, I.M.; Nakajima, V.M.; Allwood, J.W.; Stewart, D.; McDougall, G.J. Immobilized tannase treatment alters polyphenolic composition in teas and their potential anti-obesity and hypoglycemic activities in vitro. Food Funct. 2016, 7, 3920-3932. [CrossRef] [PubMed]

11. Zhong, Z.; Dong, Z.; Yang, L.; Chen, X.; Gong, Z. Inhibition of proliferation of human lung cancer cells by green tea catechins is mediated by upregulation of let-7. Exp. Ther. Med. 2012, 4, 267-272. [CrossRef] [PubMed]

12. Larsen, C.A.; Bisson, W.H.; Dashwood, R.H. Tea catechins inhibit hepatocyte growth factor receptor (MET kinase) activity in human colon cancer cells: Kinetic and molecular docking studies. J. Med. Chem. 2009, 52, 6543-6545. [CrossRef] [PubMed]

13. Yang, F.; Oz, H.S.; Barve, S.; De Villiers, W.J.; McClain, C.J.; Varilek, G.W. The green tea polyphenol (-)-epigallocatechin-3-gallate blocks nuclear factor- $\kappa B$ activation by inhibiting I $\kappa B$ kinase activity in the intestinal epithelial cell line IEC-6. Mol. Pharm. 2001, 60, 528-533.

14. Narumi, K.; Sonoda, J.I.; Shiotani, K.; Shigeru, M.; Shibata, M.; Kawachi, A.; Tomishige, E.; Sato, K.; Motoya, T. Simultaneous detection of green tea catechins and gallic acid in human serum after ingestion of green tea tablets using ion-pair high-performance liquid chromatography with electrochemical detection. J. Chromatogr. B 2014, 945, 147-153. [CrossRef] [PubMed]

15. Lambert, J.D.; Lee, M.J.; Lu, H.; Meng, X.; Hong, J.J.J.; Seril, D.N.; Sturgill, M.G.; Yang, C.S. Epigallocatechin-3-gallate is absorbed but extensively glucuronidated following oral administration to mice. J. Nutr. 2003, 133, 4172-4177. [CrossRef] [PubMed]

16. Cai, Y.; Anavy, N.D.; Chow, H.H. Contribution of presystemic hepatic extraction to the low oral bioavailability of green tea catechins in rats. Drug Metab. Dispos. 2002, 30, 1246-1249. [CrossRef] [PubMed]

17. Krook, M.A.; Hagerman, A.E. Stability of polyphenols epigallocatechin gallate and pentagalloyl glucose in a simulated digestive system. Food Res. Int. 2012, 49, 112-116. [CrossRef] [PubMed]

18. Zhang, L.; Zheng, Y.; Chow, M.S.S.; Zou, Z. Investigation of intestinal absorption and disposition of green tea catechins by Caco-2 monolayer model. Int. J. Pharm. 2004, 287, 1-12. [CrossRef] [PubMed]

19. Krupkova, O.; Ferguson, S.J.; Wuertzkozak, K. Stability of (-)-epigallocatechin gallate and its activity in liquid formulations and delivery systems. J. Nutr. Biochem. 2016, 37, 1-12. [CrossRef] [PubMed]

20. Li, N.; Taylor, L.S.; Ferruzzi, M.G.; Mauer, L.J. Kinetic study of catechin stability: Effects of pH, concentration, and temperature. J. Agric. Food Chem. 2012, 60, 12531-12539. [CrossRef] [PubMed]

21. Lambert, J.D.; Lee, M.J.; Diamond, L.; Ju, J.; Hong, J.; Bose, M.; Newmark, H.L.; Yang, C.S. Dose-dependent levels of epigallocatechin-3-gallate in human colon cancer cells and mouse plasma and tissues. Drug Metab. Dispos. 2006, 34, 8-14. [CrossRef] [PubMed]

22. Chow, H.H.; Cai, Y.; Hakim, I.A.; Crowell, J.A.; Shahi, F.; Brooks, C.A.; Dorr, R.T.; Hara, Y.; Alberts, D.S. Pharmacokinetics and safety of green tea polyphenols after multiple-dose administration of epigallocatechin gallate and polyphenon E in healthy individuals. Clin. Cancer Res. 2003, 9, 3312-3319. [PubMed]

23. Chow, H.H.; Cai, Y.; Alberts, D.S.; Hakim, I.; Dorr, R.; Shahi, F.; Crowell, J.A.; Yang, C.S.; Hara, Y. Phase I pharmacokinetic study of tea polyphenols following single-dose administration of epigallocatechin gallate and polyphenon E. Cancer Epidem. Biomar. 2001, 10, 53-58.

24. Murakami, A. Dose-dependent functionality and toxicity of green tea polyphenols in experimental rodents. Arch. Biochem. Biophys. 2014, 557, 3-10. [CrossRef] [PubMed] 
25. Lin, L.C.; Wang, M.N.; Tseng, T.Y.; Sung, J.S.; Tsai, T.H. Pharmacokinetics of (-)-epigallocatechin-3-gallate in conscious and freely moving rats and its brain regional distribution. J. Agric. Food Chem. 2007, 55, 1517-1524. [CrossRef] [PubMed]

26. Catterall, F.; King, L.J.; Clifford, M.N.; Ioannides, C. Bioavailability of dietary doses of 3H-labelled tea antioxidants (+)-catechin and (-)-epicatechin in rat. Xenobiotica 2003, 33, 743-753. [CrossRef] [PubMed]

27. Warden, B.A.; Smith, L.S.; Beecher, G.R.; Balentine, D.A.; Clevidence, B.A. Catechins are bioavailable in men and women drinking black tea throughout the day. J. Nutr. 2001, 131, 1731-1737. [CrossRef] [PubMed]

28. Chen, L.; Lee, M.J.; Li, H.E.; Yang, C.S. Absorption, distribution, and elimination of tea polyphenols in rats. Drug Metab. Dispos. 1997, 25, 1045-1050. [PubMed]

29. Yang, C.S.; Chen, L.; Lee, M.J.; Balentine, D.; Kuo, M.C.; Schantz, S.P. Blood and urine levels of tea catechins after ingestion of different amounts of green tea by human volunteers. Cancer Epidem. Biomar. 1998, 7, 351-354.

30. Lambert, J.D.; Sang, S.; Yang, C.S. Biotransformation of green tea polyphenols and the biological activities of those metabolites. Mol. Pharm. 2007, 4, 819-825. [CrossRef] [PubMed]

31. Chow, H.S.; Hakim, I.A. Pharmacokinetic and chemoprevention studies on tea in humans. Pharmacol. Res. 2011, 64, 105-112. [CrossRef] [PubMed]

32. Stalmach, A.; Mullen, W.; Steiling, H.; Williamson, G.; Lean, M.E.; Crozier, A. Absorption, metabolism, and excretion of green tea flavan-3-ols in humans with an ileostomy. Mol. Nutr. Food Res. 2010, 54, 323-334. [CrossRef] [PubMed]

33. Stalmach, A.; Troufflard, S.; Serafini, M.; Crozier, A. Absorption, metabolism and excretion of Choladi green tea flavan-3-ols by humans. Mol. Nutr. Food Res. 2010, 53, 44-53. [CrossRef] [PubMed]

34. Hong, J.; Lambert, J.D.; Lee, S.H.; Sinko, P.J.; Yang, C.S. Involvement of multidrug resistance-associated proteins in regulating cellular levels of (-)-epigallocatechin-3-gallate and its methyl metabolites. Biochem. Biophys. Res. Commun. 2003, 310, 222-227. [CrossRef] [PubMed]

35. Jodoin, J.; Demeule, M.; Béliveau, R. Inhibition of the multidrug resistance P-glycoprotein activity by green tea polyphenols. BBA Mol. Cell Res. 2002, 1542, 149-159. [CrossRef]

36. Song, Q.; Li, D.; Zhou, Y.; Yang, J.; Yang, W.; Zhou, G.; Wen, J. Enhanced uptake and transport of (+)-catechin and (-)-epigallocatechin gallate in niosomal formulation by human intestinal Caco-2 cells. Int. J. Nanomed. 2014, 9, 2157-2165. [CrossRef] [PubMed]

37. Zhu, M.; Chen, Y.; Li, R.C. Oral absorption and bioavailability of tea catechins. Planta Med. 2000, 66, $444-447$. [CrossRef] [PubMed]

38. Dag, D.; Oztop, M.H. Formation and characterization of green tea extract loaded liposomes. J. Food Sci. 2017, 82, 463-470. [CrossRef] [PubMed]

39. Zou, L.Q.; Peng, S.F.; Liu, W.; Gan, L.; Liu, W.L.; Liang, R.H.; Liu, C.M.; Niu, J.; Cao, Y.L.; Liu, Z.; et al. Improved in vitro, digestion stability of (-)-epigallocatechin gallate through nanoliposome encapsulation. Food Res. Int. 2014, 64, 492-499. [CrossRef] [PubMed]

40. Shi, M.; Shi, Y.L.; Li, X.M.; Yang, R.; Cai, Z.Y.; Li, Q.S.; Ma, S.C.; Ye, J.H.; Lu, J.L.; Liang, Y.R.; et al. Food-grade encapsulation systems for (-)-epigallocatechin gallate. Molecules 2018, 23, 445. [CrossRef] [PubMed]

41. Li, Y.; Lim, L.T.; Kakuda, Y. Electrospun zein fibers as carriers to stabilize (-)-epigallocatechin gallate. J. Food Sci. 2009, 74, C233-C240. [CrossRef] [PubMed]

42. Dube, A.; Nicolazzo, J.A.; Larson, I. Chitosan nanoparticles enhance the plasma exposure of (-)-epigallocatechin gallate in mice through an enhancement in intestinal stability. Eur. J. Pharm. Sci. 2011, 44, 422-426. [CrossRef] [PubMed]

43. Ye, J.H.; Augustin, M.A. Nano- and micro-particles for delivery of catechins: Physical and biological performance. Crit. Rev. Food Sci. Nutr. 2018, 1-17. [CrossRef] [PubMed]

44. Hu, B.; Liu, X.; Zhang, C.; Zeng, X. Food macromolecule based nanodelivery systems for enhancing the bioavailability of polyphenols. J. Food Drug Anal. 2017, 25, 3-15. [CrossRef] [PubMed]

45. Yi, W.; Hao, C.; Chen, Y.; Chen, L.; Fang, Z.; Liang, L. Formation of a multiligand complex of bovine serum albumin with retinol, resveratrol, and (-)-epigallocatechin-3-gallate for the protection of bioactive components. J. Agric. Food Chem. 2017, 65, 3019-3030.

46. Li, Z.; Gu, L. Fabrication of self-assembled (-)-epigallocatechin gallate (EGCG) ovalbumin-dextran conjugate nanoparticles and their transport across monolayers of human intestinal epithelial Caco-2 cells. J. Agric. Food Chem. 2014, 62, 1301-1309. [CrossRef] [PubMed] 
47. Li, Z.; Ha, J.; Zou, T.; Gu, L. Fabrication of coated bovine serum albumin (BSA)-epigallocatechin gallate (EGCG) nanoparticles and their transport across monolayers of human intestinal epithelial Caco-2 cells. Food Funct. 2014, 5, 1278-1285. [CrossRef] [PubMed]

48. Kumar, S.; Meena, R.; Paulraj, R. Fabrication of BSA-green tea polyphenols-chitosan nanoparticles and its role in radioprotection: A molecular and biochemical approach. J. Agric. Food Chem. 2016, 64, 6024-6034. [CrossRef] [PubMed]

49. Harwansh, R.K.; Mukherjee, P.K.; Kar, A.; Bahadur, S.; Al-Dhabi, N.A.; Duraipandiyan, V. Enhancement of photoprotection potential of catechin loaded nanoemulsion gel against UVA induced oxidative stress. J. Photochem. Photobiol. B 2016, 160, 318-329. [CrossRef] [PubMed]

50. Gómez-Mascaraque, L.G.; Soler, C.; Lopez-Rubio, A. Stability and bioaccessibility of EGCG within edible micro-hydrogels. Chitosan vs. gelatin, a comparative study. Food Hydrocoll. 2016, 61, 128-138. [CrossRef]

51. Sabouri, S.; Geng, J.; Corredig, M. Tea polyphenols association to caseinate-stabilized oil-water interfaces. Food Hydrocoll. 2015, 51, 95-100. [CrossRef]

52. Sabouri, S.; Wright, A.J.; Corredig, M. In vitro, digestion of sodium caseinate emulsions loaded with epigallocatechin gallate. Food Hydrocoll. 2017, 69, 350-358. [CrossRef]

53. Haratifar, S.; Meckling, K.A.; Corredig, M. Antiproliferative activity of tea catechins associated with casein micelles, using HT29 colon cancer cells. J. Dairy Sci. 2014, 97, 672-678. [CrossRef] [PubMed]

54. Hu, S.; Wang, T.; Fernandez, M.L.; Luo, Y. Development of tannic acid cross-linked hollow zein nanoparticles as potential oral delivery vehicles for curcumin. Food Hydrocoll. 2016, 61, 821-831. [CrossRef]

55. Bhushani, J.A.; Karthik, P.; Anandharamakrishnan, C. Nanoemulsion based delivery system for improved bioaccessibility and Caco-2cell monolayer permeability of green tea catechins. Food Hydrocoll. 2016, 56, 372-382. [CrossRef]

56. Shi, M.; Huang, L.Y.; Nie, N.; Ye, J.H.; Zheng, X.Q.; Lu, J.L.; Liang, Y.R. Binding of tea catechins to rice bran protein isolate: Interaction and protective effect during in vitro digestion. Food Res. Int. 2017, 93, 1-7. [CrossRef] [PubMed]

57. Hasni, I.; Bourassa, P.; Hamdani, S.; Samson, G.; Carpentier, R.; Tajmir-Riahi, H.A. Interaction of milk $\alpha$ - and $\beta$-caseins with tea polyphenols. Food Chem. 2011, 126, 630-639. [CrossRef]

58. Zorilla, R.; Liang, L.; Remondetto, G.; Subirade, M. Interaction of epigallocatechin-3-gallate with $\beta$-lactoglobulin: Molecular characterization and biological implication. Dairy. Sci. Technol. 2011, 91, 629-644. [CrossRef]

59. Son, Y.R.; Chung, J.H.; Ko, S.; Shim, S.M. Combinational enhancing effects of formulation and encapsulation on digestive stability and intestinal transport of green tea catechins. J. Microencapsul. 2016, 33, 183-190. [CrossRef] [PubMed]

60. Chung, J.H.; Lee, S.J.; Chung, J.O.; Oh, Y.J.; Hwang, J.A.; Kim, Y.K.; Ko, S.; Shim, S.M. Effect of hydroxypropyl methyl cellulose phthalate coating on digestive stability and intestinal transport of green tea catechins. Integr. Med. Res. 2014, 3, 34-37. [CrossRef] [PubMed]

61. Huynh, N.T.; Passirani, C.; Saulnier, P.; Benoit, J.P. Lipid nanocapsules: A new platform for nanomedicine. Int. J. Pharm. 2009, 379, 201-209. [CrossRef] [PubMed]

62. Zou, L.Q.; Liu, W.; Liu, W.L.; Liang, R.H.; Li, T.; Liu, C.M.; Cao, Y.L.; Niu, J.; Liu, Z. Characterization and bioavailability of tea polyphenol nanoliposome prepared by combining an ethanol injection method with dynamic high-pressure microfluidization. J. Agric. Food Chem. 2014, 62, 934-941. [CrossRef] [PubMed]

63. Fang, J.Y.; Lee, W.R.; Shen, S.C.; Huang, Y.L. Effect of liposome encapsulation of tea catechins on their accumulation in basal cell carcinomas. J. Dermatol. Sci. 2006, 42, 101-109. [CrossRef] [PubMed]

64. Huang, Y.B.; Tsai, M.J.; Wu, P.C.; Tsai, Y.H.; Wu, Y.H.; Fang, J.Y. Elastic liposomes as carriers for oral delivery and the brain distribution of (+)-catechin. J. Drug Target. 2011, 19, 709-718. [CrossRef] [PubMed]

65. Oteiza, P.I.; Erlejman, A.G.; Verstraeten, S.V.; Keen, C.L.; Fraga, C.G. Flavonoid-membrane interactions: A protective role of flavonoids at the membrane surface? Clin. Dev. Immunol. 2005, 12, 19-25. [CrossRef] [PubMed]

66. Dube, A.; Ng, K.; Nicolazzo, J.A.; Larson, I. Effective use of reducing agents and nanoparticle encapsulation in stabilizing catechins in alkaline solution. Food Chem. 2010, 122, 662-667. [CrossRef]

67. Liang, J.; Yan, H.; Puligundla, P.; Gao, X.; Zhou, Y.; Wan, X. Applications of chitosan nanoparticles to enhance absorption and bioavailability of tea polyphenols: A review. Food Hydrocoll. 2017, 69, 286-292. [CrossRef] 
68. Tang, D.W.; Yu, S.H.; Ho, Y.C.; Huang, B.Q.; Tsai, G.J.; Hsieh, H.Y.; Sung, H.W.; Mi, F.L. Characterization of tea catechins-loaded nanoparticles prepared from chitosan and an edible polypeptide. Food Hydrocoll. 2013, 30, 33-41. [CrossRef]

69. Dube, A.; Nicolazzo, J.A.; Larson, I. Chitosan nanoparticles enhance the intestinal absorption of the green tea catechins (+)-catechin and (-)-epigallocatechin gallate. Eur. J. Pharm. Sci. 2010, 41, 219-225. [CrossRef] [PubMed]

70. Liang, R.; Chen, L.; Yokoyama, W.; Williams, P.A.; Zhong, F. Niosomes consisting of tween-60 and cholesterol improve the chemical stability and antioxidant activity of (-)-epigallocatechin gallate under intestinal tract conditions. J. Agric. Food Chem. 2016, 64, 9180-9188. [CrossRef] [PubMed]

71. Khan, N.; Bharali, D.J.; Adhami, V.M.; Siddiqui, I.A.; Cui, H.; Shabana, S.M.; Mousa, S.A.; Mukhtar, H. Oral administration of naturally occurring chitosan-based nanoformulated green tea polyphenol EGCG effectively inhibits prostate cancer cell growth in a xenograft model. Carcinogenesis 2014, 35, 415-423. [CrossRef] [PubMed]

72. Kumazawa, S.; Kajiya, K.; Naito, A.; Saitô, H.; Tuzi, S.; Tanio, M.; Suzuki, M.; Nanjo, F.; Suzuki, E.; Nakayama, T. Direct evidence of interaction of a green tea polyphenol, epigallocatechin gallate, with lipid bilayers by solid-state Nuclear Magnetic Resonance. Biosci. Biotechnol. Biochem. 2004, 68, 1743-1747. [CrossRef] [PubMed]

73. Zou, L.; Peng, S.; Liu, W.; Chen, X.; Liu, C. A novel delivery system dextran sulfate coated amphiphilic chitosan derivatives-based nanoliposome: Capacity to improve in vitro, digestion stability of (-)-epigallocatechin gallate. Food Res. Int. 2015, 69, 114-120. [CrossRef]

74. Hong, Z.; Xu, Y.; Yin, J.F.; Jin, J.; Jiang, Y.; Du, Q. Improving the effectiveness of (-)-epigallocatechin gallate (EGCG) against rabbit atherosclerosis by EGCG-loaded nanoparticles prepared from chitosan and polyaspartic acid. J. Agric. Food Chem. 2014, 62, 12603-12609. [CrossRef] [PubMed]

75. Hu, B.; Ting, Y.; Zeng, X.; Huang, Q. Cellular uptake and cytotoxicity of chitosan-caseinophosphopeptides nanocomplexes loaded with epigallocatechin gallate. Carbohyd. Polym. 2012, 89, 362-370. [CrossRef] [PubMed]

76. Zhang, H.; Jung, J.; Zhao, Y. Preparation, characterization and evaluation of antibacterial activity of catechins and catechins-Zn complex loaded $\beta$-chitosan nanoparticles of different particle sizes. Carbohyd. Polym. 2016, 137, 82-91. [CrossRef] [PubMed]

77. Fang, J.Y.; Hwang, T.L.; Huang, Y.L.; Fang, C.L. Enhancement of the transdermal delivery of catechins by liposomes incorporating anionic surfactants and ethanol. Int. J. Pharm. 2006, 310, 131-138. [CrossRef] [PubMed]

78. De Pace, R.C.C.; Liu, X.; Sun, M.; Nie, S.; Zhang, J.; Cai, Q.; Gao, W.; Pan, X.; Fan, Z.Y.; Wang, S. Anticancer activities of (-)-epigallocatechin-3-gallate encapsulated nanoliposomes in MCF7 breast cancer cells. J. Liposome Res. 2013, 23, 187-196. [CrossRef] [PubMed]

79. Wu, Z.; Guan, R.; Xiao, C.; Lyu, F.; Cao, G.; Liu, M.; Gao, J. Optimization of catechin nanoliposomes and evaluation of their antioxidant activity and cytotoxicity. Sci. Adv. Mater. 2016, 9, 697-704. [CrossRef]

80. Zhang, J.; Nie, S.; Wang, S. Nanoencapsulation enhances epigallocatechin-3-gallate stability and its anti-atherogenic bioactivities in macrophages. J. Agric. Food Chem. 2013, 61, 9200-9209. [CrossRef] [PubMed]

81. Smith, A.; Giunta, B.; Bickford, P.C.; Fountain, M.; Tan, J.; Shytle, R.D. Nanolipidic particles improve the bioavailability and alpha-secretase inducing ability of epigallocatechin-3-gallate (EGCG) for the treatment of Alzheimer's disease. Int. J. Pharm. 2010, 389, 207-212. [CrossRef] [PubMed]

82. Liao, B.; Ying, H.; Yu, C.; Fan, Z.; Zhang, W.; Shi, J.; Ying, H.; Ravichandran, N.; Xu, Y.; Yin, J.; et al. (-)-Epigallocatechin gallate (EGCG)-nanoethosomes as a transdermal delivery system for docetaxel to treat implanted human melanoma cell tumors in mice. Int. J. Pharm. 2016, 512, 22-31. [CrossRef] [PubMed]

83. Haratifar, S. Nanoencapsulation of Tea Catechins in Casein Micelles: Effects on Processing and Biological Functionalities. Environ. Sci. Pollut. R. 2012, 19, 2227-2237.

84. Li, B.; Du, W.; Jin, J.; Du, Q. Preservation of (-)-epigallocatechin-3-gallate antioxidant properties loaded in heat treated $\beta$-lactoglobulin nanoparticles. J. Agric. Food Chem. 2012, 60, 3477-3484. [CrossRef] [PubMed]

85. Zhang, J.; Zhou, X.; Yu, Q.; Yang, L.; Sun, D.; Zhou, Y.; Liu, J. Epigallocatechin-3-gallate (EGCG)-stabilized selenium nanoparticles coated with Tet- 1 peptide to reduce amyloid- $\beta$ aggregation and cytotoxicity. ACS Appl. Mater. Interface 2014, 6, 8475-8487. [CrossRef] [PubMed] 
86. Srivastava, A.K.; Bhatnagar, P.; Singh, M.; Mishra, S.; Kumar, P.; Shukla, Y.; Gupta, K.C. Synthesis of PLGA nanoparticles of tea polyphenols and their strong in vivo protective effect against chemically induced DNA damage. Int. J. Nanomed. 2013, 8, 1451-1462.

87. Lam, W.H.; Kazi, A.; Kuhn, D.J.; Chow, L.M.; Chan, A.S.; Dou, Q.P.; Chan, T.H. A potential prodrug for a green tea polyphenol proteasome inhibitor: Evaluation of the peracetate ester of $(-)$-epigallocatechin gallate [(-)-EGCG]. Bioorgan. Med. Chem. 2004, 12, 5587-5593. [CrossRef] [PubMed]

88. Lambert, J.D.; Sang, S.; Hong, J.; Kwon, S.J.; Lee, M.J.; Ho, C.T.; Yang, C.S. Peracetylation as a means of enhancing in vitro bioactivity and bioavailability of epigallocatechin-3-gallate. Drug Metab. Dispos. 2006, 34, 2111-2116. [CrossRef] [PubMed]

89. Chiou, Y.S.; Ma, N.J.L.; Sang, S.; Ho, C.T.; Wang, Y.J.; Pan, M.H. Peracetylated (-)-epigallocatechin-3-gallate (AcEGCG) potently suppresses dextran sulfate sodium-induced colitis and colon tumorigenesis in mice. J. Agric. Food Chem. 2012, 60, 3441-3451. [CrossRef] [PubMed]

90. Chiou, Y.S.; Sang, S.; Cheng, K.H.; Ho, C.T.; Wang, Y.J.; Pan, M.H. Peracetylated (-)-epigallocatechin-3-gallate (AcEGCG) potently prevents skin carcinogenesis by suppressing the PKD1-dependent signaling pathway in CD34+ skin stem cells and skin tumors. Carcinogenesis 2013, 34, 1315-1322. [CrossRef] [PubMed]

91. Landis-Piwowar, K.R.; Huo, C.; Chen, D.I.; Milacic, V.; Shi, G.; Chan, T.H.; Dou, Q.P. A novel prodrug of the green tea polyphenol (-)-epigallocatechin-3-gallate as a potential anticancer agent. Cancer Res. 2007, 67, 4303-4310. [CrossRef] [PubMed]

92. Lee, S.C.; Chan, W.K.; Lee, T.W.; Lam, W.H.; Wang, X.; Chan, T.H.; Wong, Y.C. Effect of a prodrug of the green tea polyphenol (-)-epigallocatechin-3-gallate on the growth of androgen-independent prostate cancer in vivo. Nutr. Cancer 2008, 60, 483-491. [CrossRef] [PubMed]

93. Wang, C.C.; Xu, H.; Man, G.C.W.; Zhang, T.; Chu, K.O.; Chu, C.Y.; Cheng, J.T.Y.; Li, G.; He, Y.X.; Qin, L.; et al. Prodrug of green tea epigallocatechin-3-gallate (Pro-EGCG) as a potent; anti-angiogenesis agent for endometriosis in mice. Angiogenesis 2013, 16, 59-69. [CrossRef] [PubMed]

94. Wang, J.; Man, G.C.W.; Chan, T.H.; Kwong, J.; Wang, C.C. A prodrug of green tea polyphenol (-)-epigallocatechin-3-gallate (Pro-EGCG) serves as a novel angiogenesis inhibitor in endometrial cancer. Cancer Lett. 2018, 412, 10-20. [CrossRef] [PubMed]

95. Chen, D.; Pamu, S.; Cui, Q.; Chan, T.H.; Dou, Q.P. Novel epigallocatechin gallate (EGCG) analogs activate AMP-activated protein kinase pathway and target cancer stem cells. Bioorgan. Med. Chem. 2012, 20, 3031-3037. [CrossRef] [PubMed]

96. Green, R.J.; Murphy, A.S.; Schulz, B.; Watkins, B.A.; Ferruzzi, M.G. Common tea formulations modulate in vitro digestive recovery of green tea catechins. Mol. Nutr. Food Res. 2007, 51, 1152-1162. [CrossRef] [PubMed]

97. Peters, C.M.; Green, R.J.; Janle, E.M.; Ferruzzi, M.G. Formulation with ascorbic acid and sucrose modulates catechin bioavailability from green tea. Food Res. Int. 2010, 43, 95-102. [CrossRef] [PubMed]

98. Shim, S.M.; Yoo, S.H.; Ra, C.S.; Kim, Y.K.; Chung, J.O.; Lee, S.J. Digestive stability and absorption of green tea polyphenols: Influence of acid and xylitol addition. Food Res. Int. 2012, 45, 204-210. [CrossRef]

99. Shin, S.C.; Choi, J.S. Effects of epigallocatechin gallate on the oral bioavailability and pharmacokinetics of tamoxifen and its main metabolite, 4-hydroxytamoxifen, in rats. Anti-Cancer Drug. 2009, 20, 584-588. [CrossRef] [PubMed]

100. Kitagawa, S.; Nabekura, T.; Kamiyama, S. Inhibition of P-glycoprotein function by tea catechins in KB-C2 cells. J. Pharm. Pharmacol. 2004, 56, 1001-1005. [CrossRef] [PubMed]

101. Adhami, V.M.; Malik, A.; Zaman, N.; Sarfaraz, S.; Siddiqui, I.A.; Syed, D.N.; Afaq, F.; Pasha, F.S.; Saleem, M.; Mukhtar, H. Combined inhibitory effects of green tea polyphenols and selective cyclooxygenase-2 inhibitors on the growth of human prostate cancer cells both in vitro and in vivo. Clin. Cancer Res. 2007, 13, 1611-1619. [CrossRef] [PubMed]

102. Fujiki, H.; Sueoka, E.; Watanabe, T.; Suganuma, M. Synergistic enhancement of anticancer effects on numerous human cancer cell lines treated with the combination of EGCG, other green tea catechins, and anticancer compounds. J. Cancer Res. Clin. 2015, 141, 1511-1522. [CrossRef] [PubMed]

103. Lambert, J.D.; Hong, J.; Kim, D.H.; Mishin, V.M.; Yang, C.S. Piperine enhances the bioavailability of the tea polyphenol (-)-epigallocatechin-3-gallate in mice. J. Nutr. 2004, 134, 1948-1952. [CrossRef] [PubMed] 
104. Yang, R.; Sun, G.; Zhang, M.; Zhou, Z.; Li, Q.; Strappe, P.; Blanchard, C. Epigallocatechin gallate (egcg) decorating soybean seed ferritin as a rutin nanocarrier with prolonged release property in the gastrointestinal tract. Plant Food Hum. Nutr. 2016, 71, 277-285. [CrossRef] [PubMed]

105. Scandlyn, M.J.; Stuart, E.C.; Somers-Edgar, T.J.; Menzies, A.R.; Rosengren, R.J. A new role for tamoxifen in oestrogen receptor-negative breast cancer when it is combined with epigallocatechin gallate. Br. J. Cancer 2008, 99, 1056-1063. [CrossRef] [PubMed]

106. Zhang, X.; Zhang, H.; Tighiouart, M.; Lee, J.E.; Shin, H.J.; Khuri, F.R.; Yang, C.S.; Chen, Z.; Shin, D.M. Synergistic inhibition of head and neck tumor growth by green tea (-)-epigallocatechin-3-gallate and EGFR tyrosine kinase inhibitor. Int. J. Cancer 2010, 123, 1005-1014. [CrossRef] [PubMed]

107. Milligan, S.A.; Burke, P.; Coleman, D.T.; Bigelow, R.L.; Steffan, J.J.; Carroll, J.L.; Williams, B.J.; Cardelli, J.A. The green tea polyphenol EGCG potentiates the antiproliferative activity of c-Met and epidermal growth factor receptor inhibitors in non-small cell lung cancer cells. Clin. Cancer Res. 2009, 15, 4885-4894. [CrossRef] [PubMed]

108. Choi, J.S.; Burm, J.P. Effects of oral epigallocatechin gallate on the pharmacokinetics of nicardipine in rats. Arch. Pharm. Res. 2009, 32, 1721-1725. [CrossRef] [PubMed]

109. Ferreira, A.; Rodrigues, M.; Marques, A.; Falcão, A.; Alves, G. Influence of the dual combination of silymarin and (-)-epigallocatechin gallate, natural dietary flavonoids, on the pharmacokinetics of oxcarbazepine in rats author names and affiliations. Food Chem. Toxicol. 2017, 106, 446-454. [CrossRef] [PubMed]

110. Chung, J.H.; Choi, D.H.; Choi, J.S. Effects of oral epigallocatechin gallate on the oral pharmacokinetics of verapamil in rats. Biopharm. Drug Dispos. 2009, 30, 90-93. [CrossRef] [PubMed]

111. Nakagawa, K.; Nakayama, K.; Nakamura, M.; Sookwong, P.; Tsuduki, T.; Niino, H.; Kimura, F.; Miyazawa, T. Effects of co-administration of tea epigallocatechin-3-gallate (EGCG) and caffeine on absorption and metabolism of EGCG in humans. Biosci. Biotechnol. Biochem. 2009, 73, 2014-2017. [CrossRef] [PubMed]

112. Lambert, J.D.; Kwon, S.J.; Ju, J.; Bose, M.; Lee, M.J.; Hong, J.; Hao, X.; Yang, C.S. Effect of genistein on the bioavailability and intestinal cancer chemopreventive activity of (-)-epigallocatechin-3-gallate. Carcinogenesis 2008, 29, 2019-2024. [CrossRef] [PubMed]

113. Zhou, D.H.; Wang, X.; Yang, M.; Shi, X.; Huang, W.; Feng, Q. Combination of low concentration of (-)-epigallocatechin gallate (egcg) and curcumin strongly suppresses the growth of non-small cell lung cancer in vitro and in vivo through causing cell cycle arrest. Int. J. Mol. Sci. 2013, 14, 12023-12036. [CrossRef] [PubMed]

114. Somers-Edgar, T.J.; Scandlyn, M.J.; Stuart, E.C.; Le Nedelec, M.J.; Valentine, S.P.; Rosengren, R.J. The combination of epigallocatechin gallate and curcumin suppresses ER $\alpha$-breast cancer cell growth in vitro and in vivo. Int. J. Cancer 2010, 122, 1966-1971. [CrossRef] [PubMed]

115. Liang, G.; Tang, A.; Lin, X.; Li, L.; Zhang, S.; Huang, Z.; Tang, H.; Li, Q.Q. Green tea catechins augment the antitumor activity of doxorubicin in an in vivo mouse model for chemoresistant liver cancer. Int. J. Oncol. 2010, 37, 111-123. [PubMed]

116. Oz, H.S.; Chen, T.S. Green-tea polyphenols downregulate cyclooxygenase and Bcl-2 activity in acetaminophen-induced hepatotoxicity. Digest. Dis. Sci. 2008, 53, 2980-2988. [CrossRef] [PubMed]

Sample Availability: Samples of the compounds are not available from the authors.

(C) 2018 by the authors. Licensee MDPI, Basel, Switzerland. This article is an open access article distributed under the terms and conditions of the Creative Commons Attribution (CC BY) license (http:// creativecommons.org/licenses/by/4.0/). 